\title{
Performance Analysis of a Standalone PV-Wind-Diesel Hybrid System using ANFIS based Controller
}

\author{
Ashmi \\ Electrical and Electronics \\ Engineering Department \\ UIET, Panjab University \\ Chandigarh
}

\author{
Manoj Kumar Sharma \\ Electrical and Electronics \\ Engineering Department \\ UIET, Panjab University \\ Chandigarh
}

\author{
Sabhyata Uppal Soni \\ Electrical and Electronics \\ Engineering Department \\ UIET, Panjab University \\ Chandigarh
}

\begin{abstract}
Renewable energy has attracted the interests of researchers all around the world. The major challenge is to combine various existing sources in a single model so as to extract the usefulness of each of them while complementing each others weaknesses. This paper proposes a method to integrate solar photovoltaic system, wind turbine system and diesel generator connected to a load. A dump load is also connected to the system to absorb the excess power. The hybrid system model has been developed in MATLAB/Simulink. An Adaptive Neuro Fuzzy Inference System (ANFIS) based controller has been designed and the system is analysed in terms of the power generation and consumption. The results obtained are encouraging in terms of their stability.
\end{abstract}

\section{Keywords}

Hybrid system, Adaptive Neuro Fuzzy Inference System (ANFIS), Maximum Power Point Tracking (MPPT), consumer load, dump load.

\section{INTRODUCTION}

Energy plays an indispensable role in the growth and development of a nation. According to the Energy Information Administration, the world's energy consumption is increasing by $2.3 \%$ every year [1]. The increase in energy demand has led to the generation of power locally using renewable energy sources such as solar, wind, hydro that are tenable, cost-effective and environment friendly[2]-[3].With the introduction of renewable power generation sources, the dependence on coal and petroleum as the primary energy producing sources has decreased. This has led to the reduction in the emission of green house gases [4]-[5].

The use of an individual renewable energy source for generating power may result in over-sizing of the system thereby increasing the system design cost. Also, the power generation from these sources is unpredictable because of the instantaneous fluctuations in the weather and environmental conditions [6]. This has led to the research in hybrid systems that can be made by integrating two or more renewable energy sources with a conventional energy source and a backup supply. Such a system can be PV/wind/hydro or a combination of them with backup devices such as diesel generator [7].The combination enhances the efficiency and output capability of the system.

Several authors have analysed the evaluation of hybrid systems using different performance models, optimisation tools and techniques [8]-[11]. The development of power converters and maximum power point trackers has been discussed in [12]-[13]. An optimal control strategy for the power dispatch in PV-Diesel-Battery to heat pump water heaters was developed in [14]. The modelling and simulation of a medium penetration wind turbine with diesel generator and a battery storage system was carried out in [15]. So far the research done has focused only on specific sub-sets; for example, a system with only wind and diesel have been considered in [16], some have taken a combination of PV, Diesel and Battery, while some have considered storage less renewable energy hybrid systems[17].

Artificial Intelligence based techniques are increasingly used in renewable energy systems [18]. They offer a adaptable control and are used in non-linear systems. The arbitrary data can be interpolated and extrapolated with high delicacy, once proper training is carried out. Some applications of fuzzy logic are presented in [19]-[20] and the use of neural networks is presented in [21]-[22]. The adaptive neuro fuzzy inference system (ANFIS) combines the neural networks and fuzzy logic and this integration results in the most powerful AI technique.

This paper carries out the modelling and simulation of a hybrid system consisting of a solar photovoltaic system, wind turbine generator, diesel generator, and consumer load. An ANFIS based controller has been designed and the the system is analysed in terms of the power generation and consumption. The proposed technique offers robustness and precise control.

The paper is organised as follows.Section 2 presents the proposed hybrid system model and its components, section 3 presents the procedure for designing and selection of components, section 4presents the designing of the ANFIS based controller, section 5 presents the modelling and simulation of the hybrid system and section 6 concludes the paper. 


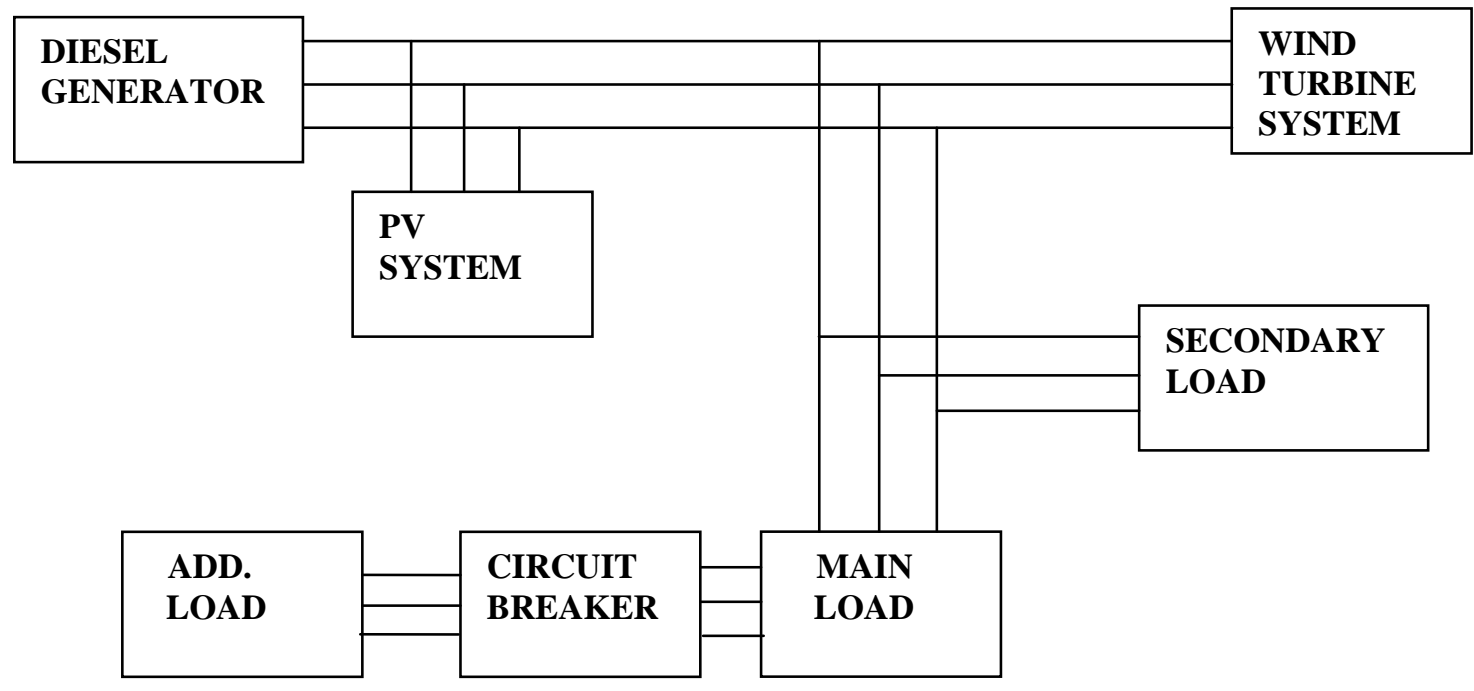

Fig.1: Hybrid System Model

\section{HYBRID SYSTEM MODEL AND ITS COMPONENTS}

The proposed model of the PV-Wind-Diesel hybrid system is shown in Fig.1. The mathematical models of the system's components are described as follows:

\subsection{PV System}

The PV system consists of a PV array, boost converter and a solar inverter. The PV array has parallel strings of silicon, gallium arsenide or cadmium sulphide to absorb and convert sunlight into electricity [23]. A boost converter is used for stepping the input voltage from supply to the load. The inverter is used to change the electric current from DC to AC. The power generated by a solar PV system is given as [24]

$p_{P V V}=a_{P V V} \times \eta_{P V V} \times \int_{T_{1}}^{T_{2}} i(t) \times g(t) \times d t$

Where; $\boldsymbol{a}_{P V V}$ is the area of the PV generator $\left(\mathrm{m}^{2}\right) ; \eta_{P V V}$ is the efficiency, $\mathrm{i}$ is the irradiance $\left(\mathrm{kWh} / \mathrm{m}^{2}\right)$ and $\mathrm{g}(\mathrm{t})$ is the radiance density. The V-I characteristics of the solar cell are non-linear and depends on the irradiation from the sun and temperature of the cell. . The location of maximum power point is unknown but it can be determined with the help of calculation models and search algorithms. Therefore, Incremental Conductance Maximum Power Point Tracking (MPPT) technique is used in this work for maximizing the generated power.

\subsection{Wind turbine system}

The wind energy system is used to convert the kinetic energy of wind into electrical energy. The power and torque generated by a wind turbine is given as

$p_{w}=0.5 \times \rho \times a_{w} \times c_{w} \times \eta_{w} \times \int_{t_{1}}^{t_{2}} v^{3}(t) \times g(t) \times d t$

$\tau=\frac{p_{w}}{\omega}$

Where; $\rho$ is the air density $\left(\mathrm{kg} / \mathrm{m}^{3}\right) ; a_{w}$ is the area swept by the blades $\left(m^{2}\right) ; C_{P, W T}$ is the coefficient of performance ; $\eta_{w}$ is the system's efficiency; $v$ is the velocity of $\operatorname{wind}(\mathrm{m} / \mathrm{s})$; $\mathrm{g}(\mathrm{t})$ is the wind probability density function; $\boldsymbol{\omega} \boldsymbol{\omega}$ is the speed of rotor; $c_{w}$ is a function of blade length and tip speed ratio. In this work, since there is no pitch control of the wind turbine generator, therefore, $c_{w}$ depends only on the tip speed ratio (TSR) which is given as

$$
T S R=\frac{\omega}{v} r
$$

Where $r$ is the length of the blade [25].

\subsection{Diesel Generator}

The diesel generator consists of two main parts i.e. generator and a prime mover. The prime mover supplies the power demand at a constant frequency and the synchronous generator helps in keeping the voltage constant at all load conditions. The frequency is maintained at a constant value by keeping the speed of the rotor constant with the governor. The synchronous generator controls the excitation current that in turn controls the output voltage[26]. The variation in the frequency indicates the balance in active power maintained by the governor and the variation in voltage indicates the balance in reactive power maintained through the excitation of the generator.

\subsection{Consumer Load}

A constant load of $500 \mathrm{~kW}$ and an additional load of $100 \mathrm{~kW}$ is connected to the system.

\subsection{Dump Load}

When the total power generation exceeds the consumption, there is excess power. The dump load is connected to the system for absorbing the excess power. There are eight three phase resistors that are connected with the GTO switches[27]. The combination of the resistors and switches is a series combination and resistor values succeed in an eight bit binary progression. The power consumed by the dump load is given as:

$$
\left(Z_{0}+Z_{1} 2^{1}+Z_{2} 2^{2}+\ldots \ldots+Z_{7} 2^{7}\right) \cdot p=x_{n} \cdot p
$$

i.e. the power can be increased from 0 to $255 \mathrm{p}$ and $\mathrm{p}$ is the power that corresponds to least significant bit [27]. 


\section{SYSTEM CONFIGURATION}

The standalone hybrid system is designed with the main load of $500 \mathrm{~kW}$ and an additional load of $100 \mathrm{~kW}$ at 0.8 lagging power factor.

\subsection{Selection of Rating of PV system}

The rating of the PV array is $300 \mathrm{~kW}$ with solar irradiance of $1000 \mathrm{~W} / \mathrm{m}^{2}$ and $25^{\circ} \mathrm{C}$ temperature. A $5 \mathrm{kHz}$ DC-DC boost converter is designed to increase the voltage. A $1980 \mathrm{~Hz}, 3-$ level, 3-phase voltage source converter (VSC) is designed to convert DC into AC.

\subsection{Selection of Rating of Synchronous Machine}

A Salient Pole Rotor type synchronous machine is selected with rated power as $300 \mathrm{kVA}$, voltage of $480 \mathrm{~V}$ and $60 \mathrm{~Hz}$ frequency.

\subsection{Selection of Rating of Wind Turbine}

The induction generator is driven by a $275 \mathrm{kVA}, 480 \mathrm{~V}$ wind turbine and the wind speed is kept at a constant value of $10 \mathrm{~m} / \mathrm{s}$.

\subsection{Dump Load}

In dump load, there are are eight three phase resistors that are connected with the GTO switches. The capacity of the dump load varies from $0-446.25 \mathrm{~kW}$.

\section{DESIGNING OF ANFIS BASED CONTROLLER}

ANFIS is a graphical network representation of Sugeno-type fuzzy inference systems which have neural learning capabilities.

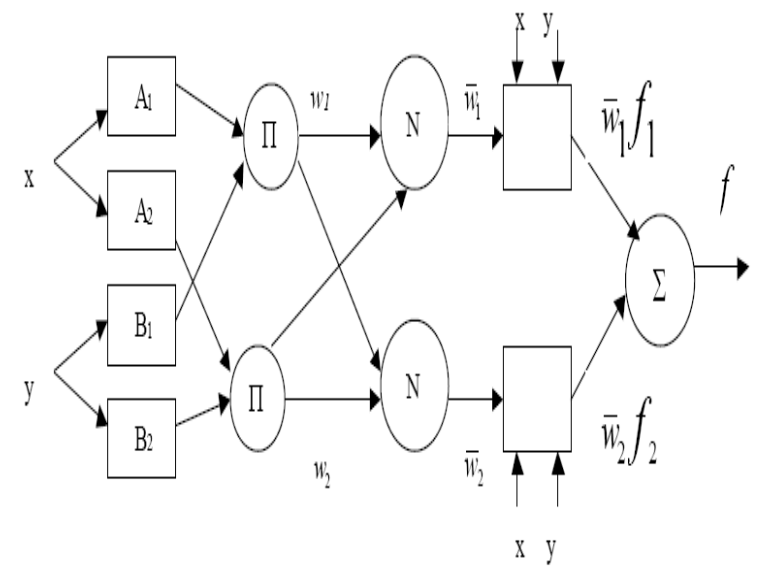

Fig. 2: Structure of ANFIS

The network has various nodes with specified functions collected in layers. The fuzzy inference system can be trained and tuned with the help of ANFIS. During the training process, the membership functions are optimised on the basis of the input/output data.The structure of the ANFIS network is shown in fig.2. It usually consists of five layers.

For designing, the output of the proportional integral (PI) controller is taken as the input training data set for the ANFIS. Table 2 shows the specifications for the design of the ANFIS based controller:
Table 1: Design specifications for ANFIS controller

\begin{tabular}{|c|c|}
\hline Number of inputs & 1 \\
\hline Number of outputs & 1 \\
\hline Number of membership functions & 5 \\
\hline Type of membership function & trimf \\
\hline Number of epocs & 60 \\
\hline Error & $0.93 \mathrm{e}-5$ \\
\hline
\end{tabular}

\section{MODELLING AND SIMULATION}

A hybrid system model is developed in MATLAB/Simulink version 15 and the simulation is carried out with the help of ode 45 solver. The controller for the system is designed based on the Adaptive Neuro Fuzzy Inference System with the help of fuzzy logic toolboxes. The power output from the wind turbine is $206 \mathrm{~kW}$ according to a wind speed of $10 \mathrm{~m} / \mathrm{s}$, but due to the losses occuring in the asynchronous machine,it produces $200 \mathrm{~kW}$. The output of the solar photovoltaic system is a function of solar irradiance and temperature. The solar irradiance is selected as a constant valued irradiance. The load is satisfied in such a way that maximum power is extracted from the renewable energy sources while taking least power from the diesel generator in order to maintain the power balance. The diesel generator is used to maintain the power balance in case of load fluctuations or during the peak demand. A dump load is also connected to absorb the excess power in case the generation exceeds the demand. The simulation is carried out in order to verify the proposed model.

\section{Case I - Constant Load}

Fig. 3 shows the power generated by the wind turbine system when a constant load of $500 \mathrm{~kW}$ is connected. When the wind turbine generator is started initially, oscillations occur in the system. At $\mathrm{t}=0.2 \mathrm{sec}$, the system attains steady state and produces nominal power i.e. $200 \mathrm{~kW}$.Fig. 4 shows the power generated by solar photovoltaic system. The PV system is producing $275 \mathrm{~kW}$. Fig. 5 shows the power generated by the diesel generator. With the sudden application of load, the diesel initially generates more power but after $t=0.2 \mathrm{sec}$, the system supplies a power of $50 \mathrm{~kW}$ to the system. Thus, the generation from all the three sources satisfies the load demand. The excess power is consumed by the dump load. Thus, the power balance is maintained. The frequency oscillates from $60.4 \mathrm{~Hz}$ to $59.8 \mathrm{~Hz}$ and stabilizes to $60 \mathrm{~Hz}$ after $\mathrm{t}=0.2 \mathrm{sec}$ as shown in Fig.7. 


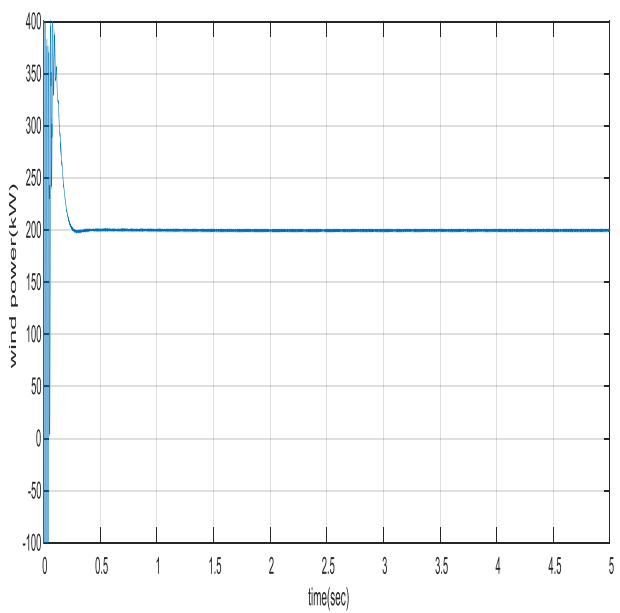

Fig.3: Power generated by wind turbine system for a constant load $(\mathbf{k W})$

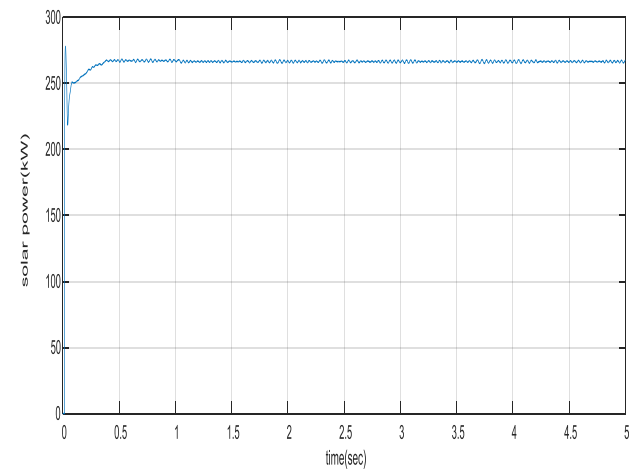

Fig.4: Power generated by PV system for a constant load $(\mathbf{k W})$

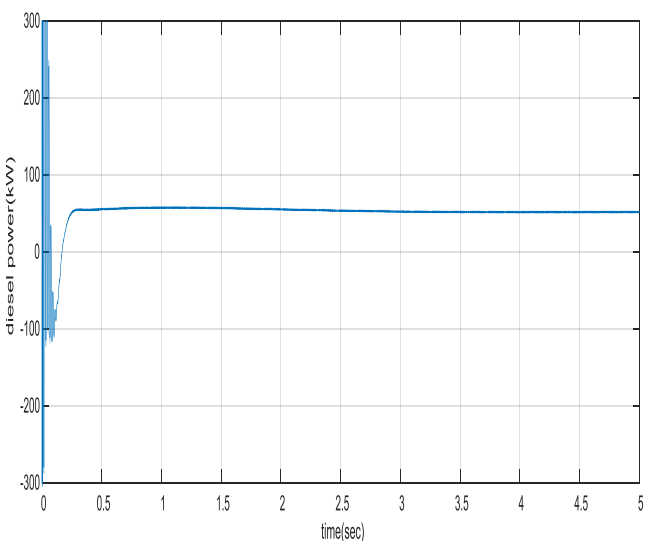

Fig.5: Power generated by diesel generator for a constant $\operatorname{load}(\mathbf{k W})$

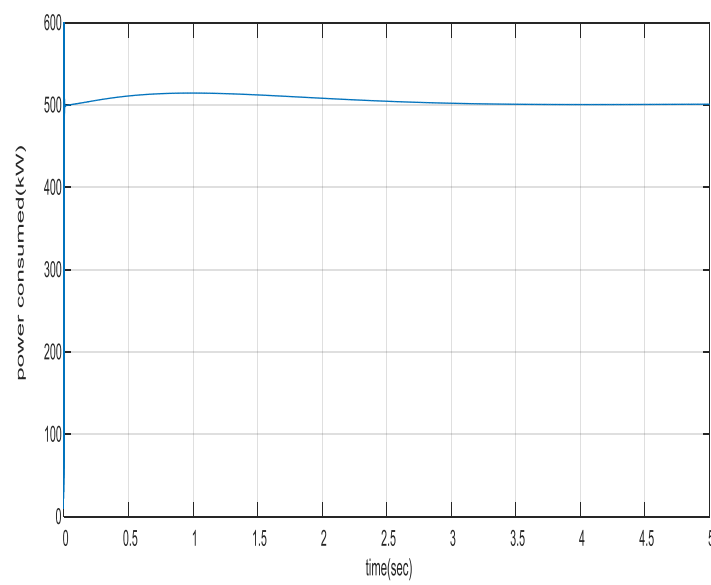

Fig. 6 Power consumed by the load (kW)

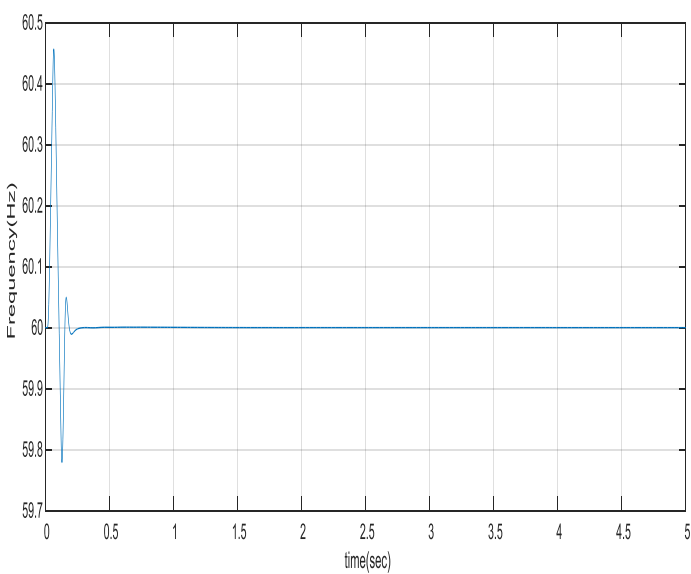

Fig.7 Frequency $(\mathrm{Hz})$

\section{CaseII -When the load is varied}

Fig.8 shows the power generated by the wind turbine. At $\mathrm{t}=2$ $\mathrm{sec}$, an additional load of $100 \mathrm{~kW}$ is added to the system i.e. the total load connected to the system is now increased to $600 \mathrm{~kW}$. The wind turbine generator, the solar photovoltaic system and the diesel generator produces power in such a way that the generated power is equal to the power consumed. During the sudden increase or decrease in the load the diesel generator acts as a back up supply and supplies the deficit power. The waveforms of the powers generated and supplied are shown in fig. 8 to fig. 11 .

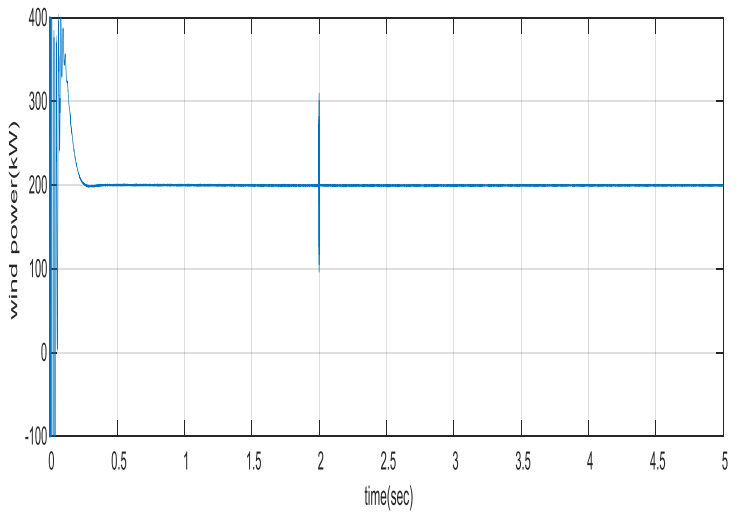

Fig.8 Power generated by wind turbine system when load is increased $(\mathrm{kW})$ 


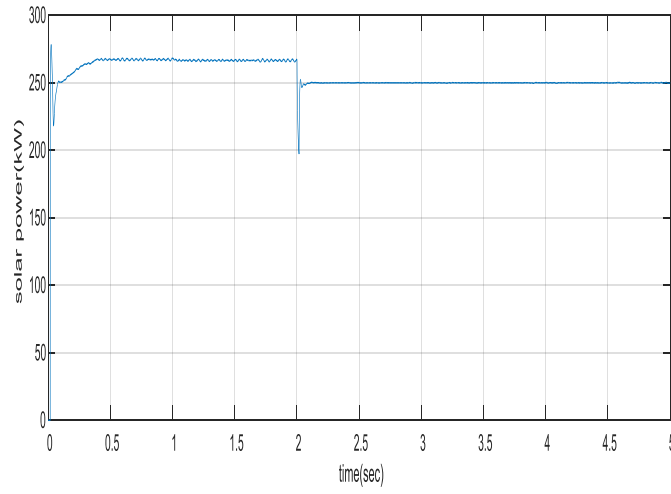

Fig.9: Power generated by PV system when load is increased $(\mathbf{k W})$

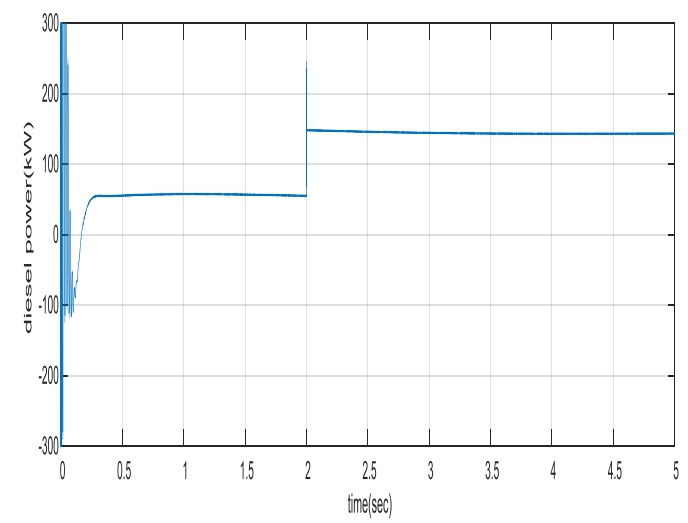

Fig.10: Power generated by the diesel generator when load is increased $(\mathrm{kW})$

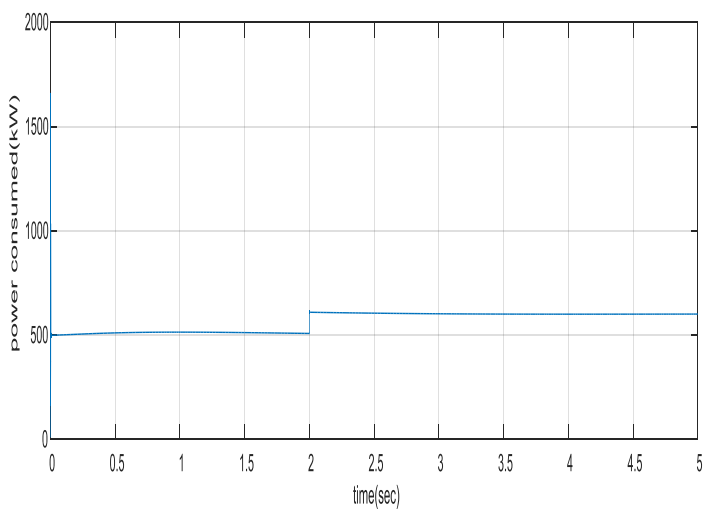

Fig.11: Power consumed by the load $(\mathrm{kW})$

\section{CONCLUSIONS}

Renewable energy sources are clean power generation sources and their integration reduces the use of conventional energy sources like diesel generator resulting in lower fuel costs and carbon emissions. This paper presents the integration of solar and wind turbine system along with the diesel generator as a backup supply. An ANFIS based controller has been designed and the system performance is analysed in terms of power balance and stability considering constant load and variable loads. In order to satisfy the load demand, priority is given to the renewable generation sources and the diesel generator works only to supply the deficit power in order to maintain the power balance. Further, battery storage can also be incorporated in the system. The battery is charged by the excess power when the generation exceeds the load demand and supplies power back to the system in case of high load demand. It also helps in reducing the voltage transients.

\section{REFERENCES}

[1] U.S Energy Information Administration, 'International EnergyOutlook2011',http://www.eia.gov/forecasts/arch ive/ieo11 (Accessed December 12,2014).

[2] Mahmoud, M.Ibrik, I.H ; 'Techni-economic feasibility of energy supply of remote villages in Palestine by PV systems, diesel generators and electric grid',Renew. Sust.Energy Rev.,2006, Vol.10, pp.128-138.

[3] Tazvinga, H.Xia, X.Zhu; 'Optimal energy management strategy for distributed energy resources', Energy Procedia,2014, Vol.61, pp.1331-1334.

[4] Post, H.N., Thomas, M.G; ' Photovoltaic systems for current and future applications', Solar Energy ,1998, Vol.41, pp.465-473.

[5] Shaahid, S.M., Elhadidy,M.A.; 'Economic analysis of a hybrid photovoltaic-diesel battery power systems for residential loadsin hot regions-a step to clean future', Renew.Sust. Energy Rev.,2008, Vol.10, pp.488-503.

[6] Bhandari, B.Lee,K-T,Cho,Y-M Lee C.S. Song, C.K.et al.; 'Hybridisation of multiple renewable power sources for remotevillageelectrification',Proc.OftheInternationalSym posium on Green Manufacturing and applications,2013.

[7] Bajpai P, Dash V; 'Hybrid renewable energy systems for power generation in stand alone applications', Renew Sustain Energy Rev, 2012

[8] Wei Zhou, Chengzhi Li, Lin Lu, Hongxing Yang; 'Current status of research on optimum sizing of standalone hybrid solar-wind power generation systems', Applied Energy 87,2010.

[9] Wei Zhou, Chengzhi Lou, Zhongshi Li, Lin Lu, Hongxing Yang; 'Current status of research on optimum sizing of stand-alone hybrid solar-wind power generation systems', Applied Energy 87,2010.

[10] Ahmed Mohamed, Osama Mohammed; 'Optimal sizing of stand-alone hybrid systems based on PV/WT/FC by using several methodologies', Journal of the Energy Institute 87,2014.

[11] Ghada Merei, Cornelius Berger, Dirk Uwe Sauer; 'Optimization of an off-grid hybrid PV-Wind-Diesel system with different battery technologies using genetic algorithm', Solar Energy 97,2013.

[12] M.H. Moradi,et al; ' A robust hybrid method for maximum power point tracking in photovoltaic systems',Solar Energy 94,2013, pp.266-276.

[13] C.M Hong, et al, 'Development of Intelligent MPPT control for a grid connected hybrid power generation system',Energy 50,2013,pp.270-279.

[14] Sam M. Sichilalu, Xiaohua Xia ; 'Optimal energy control of grid tied PV-diesel-battery hybrid system powering heat pump water heater', Solar Energy vol.115, 2015.

[15] R. Sebastián ,R. Peña Alzola; ' Simulation of an isolated Wind Diesel System with battery energy storage',Electric Power Systems Research 81,2011. 
[16] Sebastian R.; 'Smooth transition from wind only to wind diesel',Renewable Energy Vol.33, 2008,pp.454-466

[17] Gagnon R, Saulnier B; 'Modelling of high penetrartion no storage wind diesel system using Matlab',Global Wind power conference, 2002.

[18] A. Mellit, S. A. Kalogirou,'Artificial intelligence techniques for photovoltaic applications: A Review, Progress in Energy andCombustion Science,2008,Vol.34, pp.574-632.

[19] T. L. Kottas, Y. S. Boutalis amd A.D. Karlis, 'New maximum power point tracker for PV arrays using Fuzzy controller in close cooperation with fuzzy cognitive network',IEEE Trans. On Energy Conv., 2006, Vol.21.

[20] M.S. Kaisar, A. Anwer, S.K. Aditya and R. K. Mazumder, 'Design and simulation of Fuzzy based MPPT', Renewable Energy Prospect and Progress,2006, pp. 19-21.

[21] A. AI-Amoudi and L. Zhang, 'Application of Radial Basis Function Networks For Solar Array Modelling and Maximum Power-Point Prediction', IEEE Proceeding Generation Transmission and Distribution, 2000, Vol. 147, pp. 310-316.
[22] S. Premrudeepreechacham, and N. Patanapirom, 'SolarArray Modelling and Maximum Power Point Tracking Using Neural Networks',IEEE Bologna Power Tech Conference, 2003.

[23] Razykov,T.M.Ferekides,C.SMorel,E.Ullal,H.SUpadhyay a,H.M; ' Solar photovoltaic electricity: current status and future prospects',Solar Energy ,2011,pp.1580-1608.

[24] Hong, Y.Y Lian, R.C; 'Optimal sizing of hybrid wind/PV/diesel generation in astandalone power system using Markov based genetic algorithm',IEEE Trans, Power Deliv,2012, pp.1-13.

[25] Kanzumba Kusakana; 'Optimal scheduled power flow for distributed photovoltaic/wind/diesel generators with battery storage system.

[26] R.Sebastian; ' Smooth transition from wind only to wind diesel mode in an autonomous wind-diesel system with battery based energy storage system, Renewable Energy33,2008,pp.454-466.

[27] R. Gagnon, B.Saulniet,G. Sybille, P.Giroux; 'Modelling of a generic high penetration no storage wind-diesel system using Matlab/Power system blockset, Global windpower Conference, Paris, 2002 